\title{
Standardized sampling plan for Aphis gossypii based on the cotton cultivar, plant phenology and crop size
}

\author{
Tamíris A. Araújo ${ }^{1}$ (D) | Lúcia Helena A. Araújo ${ }^{2}$ | Nilson R. Silva ${ }^{3}$ | Carlos Eduardo A. Luz ${ }^{4}$ | \\ Ézio M. da Silva ${ }^{5}$ | Márcio D. Moreira ${ }^{1}$ | Fábio A. Suinaga ${ }^{6}$ | Marcelo C. Picanço ${ }^{1}$ | \\ Cristina S. Bastos ${ }^{4}$
}

\author{
${ }^{1}$ Departamento de Entomologia, \\ Universidade Federal de Viçosa, Viçosa, \\ Brazil \\ ${ }^{2}$ Embrapa Algodão, Campina Grande, Brazil \\ ${ }^{3}$ Núcleo de Graduação em \\ Agronomia, Universidade Federal de \\ Sergipe, Nossa Senhora da Glória, Brazil \\ ${ }^{4}$ Faculdade de Agronomia e Medicina \\ Veterinária, Instituto Central de Ciências Ala \\ Sul, Universidade de Brasília, Brasília, Brazil \\ ${ }^{5}$ Instituto de Ciências Agrárias, Universidade \\ Federal de Viçosa, Rio Paranaíba, Brazil \\ ${ }^{6}$ Embrapa Hortaliças, Brasília, Brazil

\section{Correspondence} \\ Tamíris A. Araújo, Departamento de \\ Entomologia, Universidade Federal de \\ Viçosa, Viçosa, Brazil. \\ Email: tamirisaa@gmail.com \\ Funding information \\ Conselho Nacional de Desenvolvimento \\ Científico e Tecnológico; Coordenação \\ de Aperfeiçoamento de Pessoal de Nível \\ Superior; Fundação de Amparo à Pesquisa \\ do Estado de Minas Gerais; Empresa \\ Brasileira de Pesquisa Agropecuária
}

\begin{abstract}
A standardized sampling plan is the starting point for developing a decision-making system for pest control. Aphis gossypii (Hemiptera: Aphididae) is a destructive sapfeeding pest on cotton worldwide. However, research addressing cotton cultivar, plant phenology and field size with the aim of developing a sampling plan for A. gossypii has not been done. Therefore, in this study, we developed a standardized sampling for A. gossypii as a function of these factors. To accomplish this, A. gossypii densities in four experimental cotton cultivars were sampled weekly during year one to determine the ideal aphid characteristic to sample (by individual or colony). During year one and two, A. gossypii densities were sampled weekly in the same cultivars to determine sampling unit, sampling technique and the number of samples for an A. gossypii sampling plan. Using the sample number determined, the sampling time was recorded for cotton field size of 1, 5, 10, 50,100 and 150 ha in order to estimate the sampling cost. In cotton, the count of individuals was the best characteristic for the assessment of A. gossypii. Leaves of the most apical branches for the vegetative and reproductive cotton plant stage were the best sampling units. The best sampling technique was direct counting. The cotton cultivar did not affect the development of the sampling plan. The A. gossypii sampling plan involved the evaluation of 58 samples per zone and required $20 \mathrm{~min}$ ( $<0.35 \mathrm{~min} / \mathrm{sample}$ ) for the evaluation of these samples. However, the walking time between samples was the main factor responsible for the total sampling time and cost in cotton fields, and this factor strongly depends on the size of the cotton field.
\end{abstract}

\section{KEYWORDS}

cotton aphid, decision-making, Gossypium hirsutum, integrated pest management, sampling technique, sampling unit

\section{1 | INTRODUCTION}

The cotton aphid, Aphis gossypii (Glover) (Hemiptera: Aphididae), is a destructive sap-feeding pest that causes economic damage in many crops worldwide, including melon, cucumber, pumpkin, tomato, pawpaw and cotton (CABI, 2018; Cao, Zhang, Gao, Liang, \& Guo, 2008; Li et al., 2013). In cotton, A. gossypii may cause indirect damage by the transmission of the persistent circulative cotton leafroll dwarf virus (CLRDV) and cotton anthocyanosis virus (CAV), which cause cotton blue disease and cotton anthocyanosis disease, 
respectively (Corrêa et al., 2005). The cotton aphid may also cause direct damage by sap-feeding (sucking) on cotton plant tissues (Fernandes et al., 2012; Ramalho et al., 2012). In addition, during this sucking process, excessive excretion of carbohydrates derived from the phloem sap favours the incidence of sooty mould fungus (Bachmann, Nault, \& Fleischer, 2014; Fernandes et al., 2012). The presence of this fungus on leaves affects the plant's photosynthetic activity, and its presence on fibres decreases boll quality (Chamuene et al., 2018; Malaquias et al., 2017).

Although there are alternative pest control methods, insecticide use remains the primary method to control A. gossypii, (Li et al., 2013; Radcliffe, Hutchison, \& Cancelado, 2009; Zhang et al., 2015). However, excessive insecticide use has increased the number of cases of field control failure (e.g., Australia), outbreaks of cotton aphids through the removal of natural enemies and reduced efficacy of chemical control due to resistance development (Cao et al., 2008; Herron, Powis, \& Rophail, 2001). Furthermore, this excessive insecticide use has contributed to environmental toxicity and human poisoning (Kerns, Yates, \& Baugh, 2015).

In this context, the use of decision-making systems for the control of A. gossypii in integrated pest management (IPM) programmes can reduce insecticide use in cotton (Bueno et al., 2011). Sampling plans are essential components of the decision-making systems in IPM programmes (Lima et al., 2017). Sampling plans can be conventional or sequential. The conventional plan can also be called "standardized sampling plan" because the number of samples is fixed, whereas in the sequential plan, the number of samples varies. The standardized sampling plan is the starting point for developing a decision-making system for pest control and can also be used to validate sequential sampling plans (Naranjo \& Castle, 2010; Pereira et al., 2016). Standardized sampling plans are determined based on the aphid characteristic (e.g., individual or colony), units, techniques and number of samples (Rosado et al., 2014). These determinants, in turn, provide representative, accurate, quick and low-cost sampling (Lima et al., 2017; Rosado et al., 2014).

For pest sampling, the crop area needs to be divided into zones. In these zones, the characteristics of topographical relief, plant cultivar, phenological plant stage and agricultural systems should be uniform. The zones might have an area of less than one to hundreds of hectares, and the plants in each zone might have different absolute pest densities based on the specific features of the zone (Miranda, 2010; Moura et al., 2018). In this sense, the sampling plan used should have a sample size that allows the determination of relative densities that represent the absolute pest density in both small and large zones (Moura et al., 2018; Pinto et al., 2017). To evaluate the samples, the distance covered in small zones is less than that covered in large zones. Throughout the world, cotton fields range from a few to thousands of hectares (Cao et al., 2008; Kerns et al., 2015; Malaquias et al., 2017). Cotton pest sampling plans should be adapted to each of these situations based on the recommendation that the cotton field zones used for samplings plans should not be larger than 150 ha (Miranda, 2010).
Due to the importance of cotton, a few studies have attempted to contribute to the development of decision-making systems for A. gossypii IPM programmes. Kerns et al. (2015) determined economic thresholds for A. gossypii on cotton based on the number of aphids per leaf. Fernandes, Spessoto, Degrande, and Rodrigues (2011) developed a sequential sampling plan for A. gossypii on cotton based on the number of aphid colonies. However, this sampling plan was determined for only one cotton cultivar without considering the different phenological stages of the cotton plant. In addition, this sampling plan did not consider the ideal aphid characteristic (individual or colony), units and techniques for the evaluation of A. gossypii populations, as well as the sampling time and cost.

Therefore, in this study, we developed a standardized sampling plan for the cotton aphid, A. gossypii, which depends on the specific phenological plant stage and the cotton cultivar. To develop these sampling plans, we divided this study into five parts. We determined the ideal (a) aphid characteristic, (b) sample unit and (c) sampling technique for assessing A. gossypii in cotton, as well as (d) the number of samples that should be included in the standardized sampling plan and (e) the sampling time and cost required for sampling A. gossypii in different sized cotton fields or zones.

\section{2 | MATERIALS AND METHODS}

\section{1 | Experimental conditions}

This study was performed over two consecutive years in an experimental area belonging to the State Research Company of Paraíba (EMEPA) in Itaporanga $\left(07^{\circ} 18^{\prime} 14^{\prime \prime} \mathrm{S} 38^{\circ} 09^{\prime} 00^{\prime \prime} \mathrm{W}, 289-\mathrm{m}\right.$ altitude, semiarid climate), Paraíba state, Brazil.

The factors under study consisted of the cotton cultivar and the phenological plant stage. The cotton cultivars tested are BRS Safira (resistant), BRS Rubi and BRS Verde (tolerant), and BRS 8H (susceptible) (Smith, 2005). These cultivars were selected to assess whether cotton cultivar types with different aphid susceptibility levels influence sampling plan development. The phenological cotton plant stages tested were the vegetative (before the appearance of the first flower) and reproductive (after the appearance of the first flower or the settlement of the first boll).

The experimental design was a completely randomized design with six replications. Each cotton plot (i.e., plot of each cultivar: BRS $8 \mathrm{H}$, BRS Rubi, BRS Safira and BRS Verde) consisted of 1 ha, and the spacing between rows and plants was $1.0 \times 0.20 \mathrm{~m}$. Weeds were controlled by one herbicide application $[2.5 \mathrm{~L} /$ ha Herbadox (BASF Corporation, Hannibal MO, USA) + 1.5 L/ha Diuron (NORTOX S/A, Arapongas, $\mathrm{PR}$, Brazil)] one day after planting, and two hand hoeings (at 40 and 70 days after planting). In this study, no insecticide was applied. The aphid specimens collected were placed in glass vials $(10 \mathrm{ml})$ containing a $70 \%$ ethanol solution and identified according to Blackman and Eastop (1984).

Extension publications and recommendations for Brazilian cotton pest sampling recommend evaluating at least 100 plants per zone (Gallo et al., 2002). Therefore, in the following sections of this 

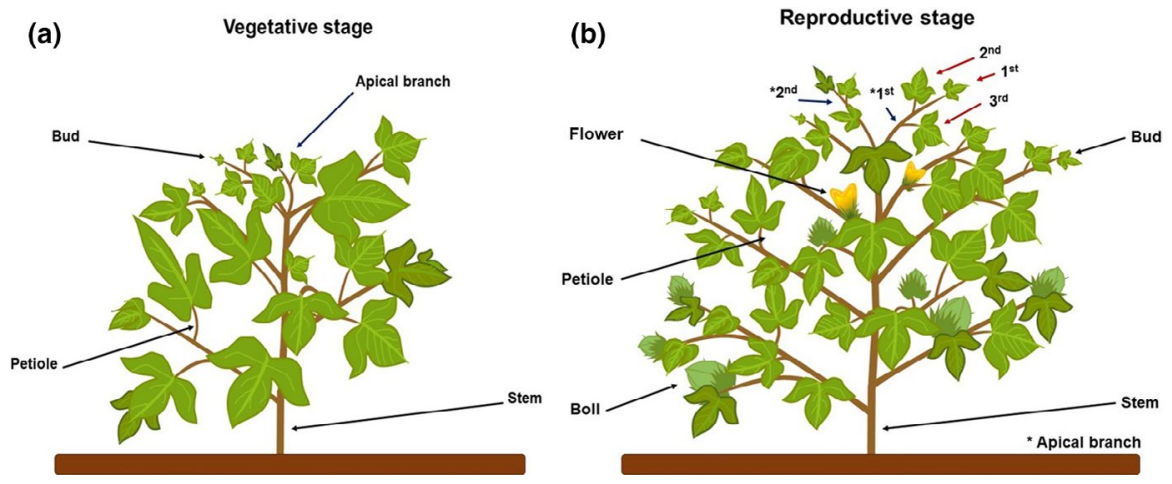

FIGURE 1 Details of the cotton plant showing the structures at the (a) vegetative and (b) reproductive stages [Colour figure can be viewed at wileyonlinelibrary.com]

study, 140 plants were evaluated. The plants were sampled per plot using the zigzag pattern, which is the typical pattern adopted for cotton pest sampling (Fernandes et al., 2011; Gallo et al., 2002).

\subsection{Selection of the aphid characteristic for assessing Aphis gossypii on cotton plants}

This section of the study was conducted according to Kerns et al. (2015), which demonstrated that the damage caused by A. gossypii is a function of the number of aphids per cotton plant (and so economic thresholds). In contrast, Fernandes et al. (2011) developed a sampling plan based on the number of colonies ( $\geq 5$ insects) of A. gossypii per cotton plant. Therefore, because the damage caused by A. gossypii is a function of the number of aphids per plant, it remains unclear whether the number of colonies reflects the total number of aphids per plant.

To answer this question, this part of the study was performed in each cotton plot during the first year. The number of $A$. gossypii individuals was evaluated on 140 plants randomly selected in each cotton plot (natural field infestations). For each evaluation, the cotton plant growth stage (i.e., vegetative or reproductive) was recorded. Correlation analyses $(p<0.05)$ were then performed among the total number of cotton aphids per plant and the number of aphid colonies per plant. The selected characteristic (i.e., colonies or individuals) was used in the following studies.

\subsection{Selection of the best sampling unit for assessing Aphis gossypii on cotton plants}

To select the sample unit, 140 plants in each cotton plot were evaluated weekly during both years. For each evaluation, the cotton plant growth stage (i.e., vegetative or reproductive) was recorded. To eliminate directional assessment trends, our evaluations were performed on plants located equidistantly (Midgarden, Youngman, \& Fleischer, 1993).

The plants were randomly selected, and all plant structures (i.e., bud, stem, petiole, leaf, flower and boll) were assessed (Figure 1). First, A. gossypii density (nymphs and adults) was determined considering the part of the plant canopy for the vegetative stage (apical nodes 1-2, median nodes 3-4 and basal nodes 5-6) and the reproductive stage (apical nodes 1-6, median nodes 7-12 and basal nodes 13-18). Next, for each plant, A. gossypii density (nymphs and adults) was determined considering the position of the leaf on the branch and the position of the branch on the main stem. The most apical branch on the main stem was labelled number 1 , the second most apical branch was labelled number 2 and so on until the plant base was reached. The most apical leaf on the distal position of the branch was labelled number 1 , the second most apical leaf was labelled number 2 and so on until the base of the branch was reached.

The evaluation of A. gossypii densities (mean $\pm S E$ ) was done using the direct counting technique and was calculated per plant canopy, branch and cotton structure (i.e., bud, stem, petiole, leave, flower and boll). The sample unit was selected using the criteria of precision and representativeness. For the criterion of precision, the sample whose aphid density presented relative variance less than $25 \%$ was selected. This was done because these units generate sampling plans with low sample numbers, which makes them feasible (Binns, Nyrop, \& Werf, 2000; Southwood, 1978). The relative variances were calculated using the following formula (1):

$$
R V=100 \times(S E / \bar{X})
$$

where $R V$ = relative variance (\%), (SE) = standard error of the $A$. gossypii mean densities and $\bar{X}=$ mean density of insects sampled.

For the criterion of representativeness, the relative density (i.e., number of aphids per leaf) that showed a positive and significant correlation $(p<0.05)$ with absolute density (total number of aphids per plant) was selected (Southwood, 1978).

\subsection{Selection of the best technique for sampling Aphis gossypii on cotton plants}

Four sampling techniques were studied: leaf beating on a white plastic tray (LBPT) $(35-\mathrm{cm}$ length $\times 30-\mathrm{cm}$ width $\times 5-\mathrm{cm}$ depth), direct counting (DC) of insects on both leaf surfaces (abaxial and adaxial), whole leaf collection in paper bags (WLCPB) and yellow stick trap (YST). These techniques were chosen because they are the most frequently 
used techniques for sampling sap-feeding insects (Jasrotia, Nataraja, Harish, Dutta, \& Savaliya, 2016; Moura et al., 2007; Pinto et al., 2017).

To select the best technique, 140 plants randomly selected from each cotton plot were evaluated weekly during both years. For each evaluation, the cotton plant growth stage (i.e., vegetative or reproductive) was recorded. To eliminate directional assessment trends, our evaluations were performed on plants located equidistantly (Midgarden et al., 1993). Because the cotton season is long, and in order to optimize data collection, all techniques were applied throughout of the plant canopy during the two years, except for the yellow stick trap that was used according to the manufacturer's recommendations. However, for the data analysis, only data corresponding to the sample unit selected on the previous section were used.

The LBPT technique consisted of placing a tray below the selected sampling unit, shaking the sample at least ten times inside the tray and then counting the fallen insects. In the DC approach, the insects on the selected sampling unit were counted. In the WLCPB method, the leaves present on the selected sampling unit were rapidly collected and placed in a paper bag for subsequent identification. The bags containing leaves were then transported to the laboratory, where the live insects on the leaf and in the bag were counted (Moura et al., 2007). The YST technique involved the counting of insects by looking at both sides of the trap.

The criteria of accuracy and representativeness were used to determine the best sampling technique (Binns et al., 2000; Southwood, 1978). According to the accuracy criterion, the sampling technique that presented RVs below $25 \%$ was selected (Southwood, 1978). The $\mathrm{RV}$ calculation followed the same procedures as that used for the selection of the best sampling unit. With respect to the representativeness criterion, the sampling technique that showed positive and significant $(p<0.05)$ correlations between the absolute and relative densities of $A$. gossypii was selected.

\subsection{Determination of the number of samples}

To determine the number of samples, 140 plants randomly selected from each cotton plot were evaluated weekly during both years. For each evaluation, the cotton plant growth stage (i.e., vegetative or reproductive) was recorded. To eliminate directional assessment trends, our evaluations were performed in plants located equidistantly (Midgarden et al., 1993). For the data analysis, only data corresponding to the sample unit and technique selected on the previous sections were used.

For each cotton cultivar and phenological plant stage, the mean and SE of the A. gossypii densities were calculated. The observed and expected frequencies of A. gossypii densities by the negative, Poisson and binomial positive distributions were calculated. The densities of A.gossypii fit a type of frequency distribution when differences between observed and expected frequencies were nonsignificant according to the chi-square test ( $p>0.05)$ (Bliss \& Owen, 1958; Young \& Young, 1998).
As previously observed in most crops, the A. gossypii densities fit a negative binomial distribution (Young \& Young, 1998). The aggregation parameter values were calculated for each cultivar using the following Equation (2):

$$
\hat{k}=\bar{x}^{-2} /\left(s^{2}-\bar{x}\right),
$$

where $\hat{k}=$ negative binomial distribution parameter, $S^{2}=$ variance of A. gossypii density sampled and $\bar{X}=$ mean.

To verify whether there was a common aggregation parameter $\left(K_{\text {common }}\right)$, the $K$ value of each cotton cultivar and phenological plant stage (i.e., vegetative and reproductive) was submitted to simple linear regression analysis (Bliss \& Owen, 1958). It was considered that the cotton cultivar/stage combination presented a $K_{\text {common }}$ when they had a significant slope and a non-significant intercept, based on the $F$ test at $p<0.05$ (Bliss \& Owen, 1958).

After having verified the existence of a $K_{\text {common }}$ among the different cotton cultivars and of the different phenological plant stages, the number of samples to compose the A. gossypii sampling plan in cotton was estimated. The number of samples was calculated according to the formula proposed by Young \& Young for the negative binomial distribution (1998) (3):

$$
N=\left\{\left(1 / C^{2}\right) \times\left[(1 / \bar{x})+\left(1 / k_{c}\right)\right]\right\},
$$

where $N=$ number of samples, $C=$ permitted error, $\bar{X}=$ population mean and $k_{c}=$ common parameter of the negative binomial distribution.

For these calculations, we employed error values of 0.05-0.25. These errors were used because sampling errors between 0.05 (5\%) and 0.25 (25\%) are considered acceptable for decision-making in integrated pest management programmes (Southwood, 1978).

\subsection{Determination of the sampling time and cost}

In these calculations, the sample size ideal for the evaluation of $A$. gossypii populations determined previously in this study (58 samples per zone) was used. The 58 samples evaluated were located equidistant in each field (Midgarden et al., 1993). The sampling was performed twice in each field, at the vegetative and reproductive stages. To determine the sampling time, samples were collected from field of 1, 5, $10,50,100$ and 150 ha because cotton fields are currently from a few to thousands of hectares; in addition, 150 ha was the largest field size used to assess the sampling of A. gossypii in cotton (Cao et al., 2008; Kerns et al., 2015; Malaquias et al., 2017; Miranda, 2010).

The sampling time for the evaluation of A. gossypii included the walking time between the different samples and the evaluation time of the pest. For each situation (walking and evaluation time), the time was recorded separately. Afterwards, the A. gossypii sampling cost was determined for one sample for each field size, based on the materials and labour cost (Pinto et al., 2017). Materials (clipboard, paper, pencil and eraser) were cost-estimated for one sampling event during a crop season ( 25 weeks). Labour cost was calculated based on the wage paid per hour to one pair of workers in Brazil (US \$4.48). 


\section{3 | RESULTS}

\subsection{Characteristic to be assessed in the sampling}

We verified that there was no correlation $(r=0.11, p=0.26)$ between the total number of $A$. gossypii individuals and the number of colonies on cotton plants of different cultivar types and of different phenological plant stages. Among the evaluated plants, we observed $23.68 \pm 2.56$ aphids per plant and $4.90 \pm 0.49$ aphid colonies per plant.

Because the damage caused by A. gossypii is a function of the number of aphids per plant (Kerns et al., 2015), and there was no correlation between the total number of individuals per plant and the number of colonies per plant, we considered the number of aphids as the characteristic for the sampling plan developed in this study.

\subsection{Sampling unit}

The results obtained to determine the sampling unit for each cotton cultivar were similar; thus, the results obtained aiming to select the best sampling unit are a summary of the data obtained for all tested cultivars (Supporting Information Tables S1-S8). The leaves of the most apical branches (first and second branch) were the best sampling unit to evaluate A. gossypii on cotton plants, at the vegetative and reproductive phenological stages (Table 1). More detailed information about A. gossypii density per plant canopy, branch and cotton structure (i.e., bud, stem, petiole, flower and boll) is shown in the Supporting Information Tables S9-S11.

Using the DC method of cotton plants, greater A. gossypii densities were detected on the second leaf from the first and second branches of the apical canopy of the cotton cultivars. The first, second and third leaves yielded relative variance values below $25 \%$, and significant positive correlations $(p<0.05)$ between the relative and absolute A. gossypii densities. Thus, the leaves of the most apical branches were the ideal unit for sampling A. gossypii populations in the cotton fields at all plant growth stages.

\section{3 | Sampling technique}

The results obtained to determine the sampling technique for each phenological cotton plant stage were similar; thus, the results of this part of the study are a summary of the data obtained for both cotton phenological stages. Among the sampling techniques considered in this study, higher A. gossypii densities were observed with the LBPT and DC method at the vegetative and reproductive stages (Table 1). The YST method, even when using different heights, did not yield higher densities of A. gossypii; thus, the results shown for the YST method constitute a summary of all YST results. The Supporting Information provides more detailed information about each YST study (Table S12). All the techniques had a relative variance value below $25 \%$ for both plant stages. However, no significant positive correlations $(p<0.05)$ were found at the vegetative or reproductive stages between the relative densities obtained with each of the tested techniques (YST, LBPT, WLCPB) and the absolute A. gossypii densities obtained through DC. The sampling technique that should be used for A. gossypii sampling is DC on the leaves of the most apical branches of the cotton plants.

\subsection{Number of samples in the sampling plan}

The results obtained to determine the number of samples required for a standardized sampling plan are shown for nymphs and adults (winged and wingless). Most of the A. gossypii densities obtained for different phenological stages and for different cotton cultivars fit a negative binomial distribution. Based on the goodness-of-fit chisquare test, all the cultivars and stages, except for the Safira cultivar at the reproductive stage, fit a negative binomial distribution (Table 1).

The regression curve of the aggregation parameter $\left(K_{\text {common }}\right)$ according to the $K$ parameter of each cultivar/stage combination presented a significant slope $(p<0.05)$ and a non-significant intercept $(p>0.05$ ) (Table 2). Thus, among A. gossypii densities in cotton fields of different cultivars types and of different phenological plant stages, there is a common aggregation parameter $\left(K_{\text {common }}=0.2786\right)$.

The error chosen to calculate the number of samples to perform the sampling of A. gossypii in cotton was $25 \%$ (Figure 2). This error was adopted because according to Southwood (1978), for pest management purposes, an error of up to $25 \%$ is admissible. Therefore, at this precision error, the standardized sampling plan for A. gossypii in the different cotton cultivars with plants at vegetative and reproductive stages requires 58 samples/zone.

\section{5 | Sampling cost and time}

The results are a summary of the data obtained for both phenological stages of the cotton plants. The sampling time required for sampling A. gossypii included the walking time between the different samples and the evaluation time (Table 3 ). The time required for assessing 58 samples was only $20 \mathrm{~min}$ ( $<0.35 \mathrm{~min} /$ sample). In contrast, the walking time between the samples ranged depending on the field size. For fields with a size of 1-150 ha, the walking time ranged from $20 \mathrm{~min}$ to $4 \mathrm{hr}$ and $05 \mathrm{~min}$. The sampling cost for one sampling of A. gossypii in an area of 1-150 ha ranged from US\$ 3.11 to 19.32 per sampling, and the final sampling time ranged from $40 \mathrm{~min}$ to $4 \mathrm{hr}$ and $25 \mathrm{~min}$.

\section{4 | DISCUSSION}

The number of aphids was the ideal characteristic for sampling A. gossypii on cotton plants. Selecting the ideal pest characteristic for sampling is the first step to develop representative and accurate samplings plans (Moura et al., 2007). In addition, understanding which characteristic represents the pest damage is the primary step for developing appropriate economic injury levels (Foresti, Bastos, 
TAB LE 1 Insect density (mean $\pm S E$ ), relative variance, Pearson's correlation coefficient $(r$ ) as a function of the leaf position in the most apical branches and sampling technique, and chi-square test $\left(\chi^{2}\right)$ between observed and expected frequencies by negative binomial, Poisson and positive binomial distributions of Aphis gossypii densities

\begin{tabular}{|c|c|c|c|c|c|c|c|c|c|}
\hline \multicolumn{9}{|c|}{ Selection of the best sampling unit } & \\
\hline \multicolumn{3}{|c|}{ Leaf (numbered from the branch apex) } & \multicolumn{3}{|c|}{ Insect density (mean $\pm S E$ ) } & \multicolumn{2}{|c|}{ Relative variance (\%) } & \multicolumn{2}{|l|}{$r$} \\
\hline \multicolumn{3}{|l|}{ 2nd } & \multicolumn{3}{|c|}{$32.42 \pm 2.83$} & \multicolumn{2}{|l|}{8.72} & \multicolumn{2}{|c|}{$0.03^{*}$} \\
\hline \multicolumn{3}{|l|}{$3 r d$} & \multicolumn{3}{|c|}{$11.56 \pm 2.27$} & \multicolumn{2}{|l|}{19.63} & \multicolumn{2}{|c|}{$0.02^{*}$} \\
\hline \multicolumn{10}{|c|}{ Selection of the best sampling technique } \\
\hline \multicolumn{3}{|l|}{ Phenologic stage } & & \multicolumn{3}{|c|}{$\begin{array}{l}\text { Insect density } \\
\text { (mean } \pm S E)\end{array}$} & \multicolumn{2}{|c|}{$\begin{array}{l}\text { Relative variance } \\
\text { (\%) }\end{array}$} & $r$ \\
\hline \multirow[t]{2}{*}{ Vegetative } & Yellow stick tr & & & & $6.43 \pm 0$ & & 6.03 & & 0.03 \\
\hline & Direct countir & & & & $60.85 \pm$ & & 9.04 & & $0.72^{*}$ \\
\hline Reproductive & Yellow stick tr & & & & $5.05 \pm 0$ & & 9.35 & & 0.00 \\
\hline & Beating plants & gainst tray & & & $74.73 \pm$ & & 9.47 & & 0.01 \\
\hline & Whole leaf co & ction in paper bags & & & $12.85 \pm$ & & 14.79 & & 0.02 \\
\hline & Direct countir & & & & $80.22 \pm$ & & 9.11 & & $0.83^{*}$ \\
\hline Fitting densities & a frequency distrik & tion & & & & & & & \\
\hline & & & Negativ & omial & Poi & & Positive & & \\
\hline Cotton cultivar & Phenologic stage & $($ mean $\pm S E)$ & $\chi^{2}$ & $d f$ & $\chi^{2}$ & $d f$ & $\chi^{2}$ & $d f$ & \\
\hline Verde & Vegetative & $15.90 \pm 0.34$ & $3.85^{\mathrm{ns}}$ & 2 & - & - & - & - & \\
\hline & Reproductive & $48.84 \pm 0.46$ & $3.94^{\mathrm{ns}}$ & 5 & - & - & $468.27^{*}$ & 1 & \\
\hline
\end{tabular}

${ }^{*}$ Significant at $p<0.05 .{ }^{\mathrm{ns}}$ Non-significant at $p<0.05$.

Fernandes, \& Silva, 2018; Moura et al., 2018; Pereira et al., 2016). Therefore, aphid counts should not only be considered as most appropriate for sampling, but also to develop economic injury levels for A. gossypii in cotton.

Leaves of the most apical branches at both phenological stages (vegetative and reproductive) were the best sampling units for sampling A. gossypii in all cotton cultivars. These leaves and branches were chosen because this enabled adequate sampling in different cotton cultivars at two phenological stages (vegetative and reproductive) and were highly representative and accurate (Moura et al., 2007; Southwood, 1978). Higher insect densities are frequently associated with a plant's structures where resources can be best exploited (food or shelter) (Cibils-Stewart, Sandercock, \& McCornack,
2015; Smith \& Chuang, 2014). Sap-feeding insects exploit the apical canopy to a greater degree because this plant structure has higher levels of water and nitrogen (Bernays, 1994). In addition, in this part of the canopy, we found tender plant tissues, such as the apical bud and youngest leaves, which are easiest to exploit (Pinto et al., 2017).

The best sampling technique was the DC for sampling A. gossypii. Only the DC technique enabled fast and high-precision sampling (relative variance $<25 \%$ ). This technique has been recommended for sampling several species of aphids and thrips, including the thrips Frankliniella schultzei and Thrips palmi (Bacci et al., 2008). The DC technique allows better visualization of the insect without disrupting it (Bacci et al., 2008). In addition, it has been reported that for sampling plans, the DC technique is best because it provides improved 
TAB LE 2 Estimation and homogeneity test for the common aggregation parameter (Kcommon) of the negative binomial distribution for the density data of Aphis gossypii from cotton cultivars

\begin{tabular}{llcr} 
Variance source & $\begin{array}{l}\text { Degrees of } \\
\text { freedom }\end{array}$ & Mean squares & \multicolumn{1}{l}{$\boldsymbol{F}$} \\
\hline Slope 1/kc & 1 & 16.69 & $13.99^{*}$ \\
\hline Intercept & 1 & 0.01 & 0.01 \\
\hline Residue & 8 & 1.19 & \\
$K_{\text {common }}=0.2786$ & & & \\
\hline
\end{tabular}

*Significant according to the $F$ test at $p<0.05$.

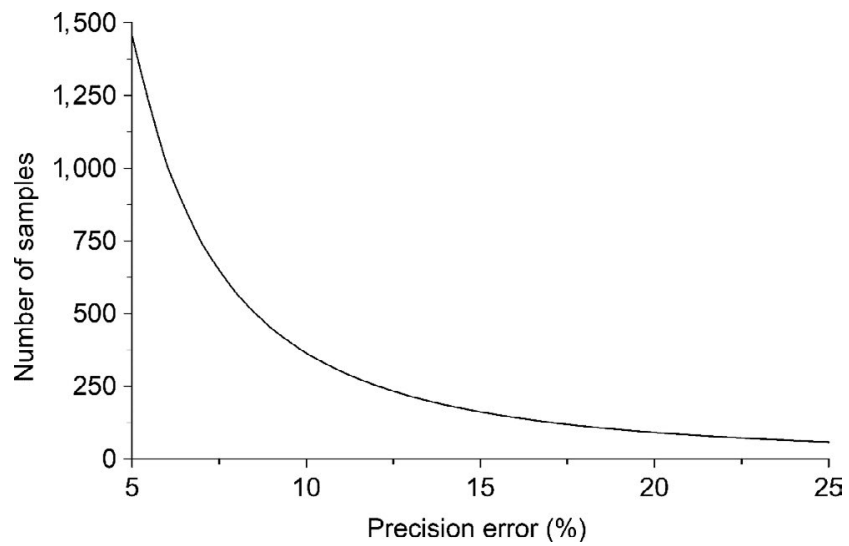

FIGURE 2 Number of samples for sampling Aphis gossypii as a function of the different levels of precision error

representativeness and faster sampling with good accuracy (Lima et al., 2017; Pereira et al., 2016; Rosado et al., 2014). Among the sampling techniques evaluated in this study, the LBPT approach, although not representative, also had higher densities of A. gossypii, possibly because this aphid cannot hold onto the plant or cannot fly when the leaves are shaken during LBPT (winged adults).

The A. gossypii density data fit a negative binomial distribution due to the high frequency of samples with extreme densities (low or high), resulting in variances higher than the average (Taylor, 1961). A single insect species might present different values for the parameter $K$ in the negative binomial distribution depending on the crop species attacked, resulting in sampling plans with different numbers of samples for each crop attacked by a specific species (Young
\& Young, 1998). Here, A. gossypii densities in the different cotton cultivar crops showed a common aggregation parameter ( $\left.K_{\text {common }}\right)$. This indicates that it is possible to obtain a reliable sampling plan for A. gossypii in cotton of different cultivars types (Rosado et al., 2014; Young \& Young, 1998). In addition, in the case of this study, the presence of a $K_{\text {common }}$ indicates that the sampling plan is flexible and can be used in cotton fields during the vegetative and reproductive stages.

The number of samples required is important because it in part determines the feasibility of a sampling plan (Lima et al., 2017). Sampling plans are feasible when they allow fast and low-cost sampling. Data collection and processing, as well as decision-making, should be performed over a period of one day or less (morning or afternoon) (Moura et al., 2007). This time period enables fast pest management decisions before the pests cause economic damage and it is essential for insects that exhibit high population growth rates, such as aphids (Bachmann et al., 2014; Ramalho et al., 2012). Therefore, the precision error of $25 \%$ was adopted because this was the smallest error that generated a feasible plan allowing the tasks of sampling, data processing and decision-making to be conducted within one day.

Sampling time includes the walking time between samples and the evaluation time for each sample. We developed a sampling plan in which 58 samples were evaluated in only $20 \mathrm{~min}$. This was possible because the DC technique associated with the selected sample unit resulted in a sampling plan that is representative, accurate and rapid (Lima et al., 2017; Rosado et al., 2014). The walking time is responsible for most of the sampling time. An area of 150 ha required a sampling time of $4 \mathrm{hr}$ and $25 \mathrm{~min}$, but the actual evaluation represents only $20 \mathrm{~min}$ of this time. Therefore, we reinforce that the selection of the sample unit and sampling technique is an important factor for developing a feasible sampling plan. In addition, it is important to observe that as the field size increases, the sampling time also increases because more is the time spent walking between the samples. The sampling cost, in turn, increases as the field size increases. In this sense, the uniqueness of this study regarding the sampling time as a function of the cotton field size highlights the importance of the field size for sampling planning.

In conclusion, the sampling plan determined in this study to evaluate A. gossypii in cotton consists of a feasible sampling plan that can be incorporated into integrated pest management programmes for different cotton cultivars, different plant phenology stages and
TABLE 3 Time and cost required for one sampling of Aphis gossypii by one pair of workers in cotton fields as a function of the area sampled

\begin{tabular}{clllc} 
Area (ha) & $\begin{array}{l}\text { Walking time } \\
\text { between samples }\end{array}$ & Evaluation time & Sampling time & $\begin{array}{l}\text { Sampling } \\
\text { cost }^{\mathrm{a}} \text { (US \$) }\end{array}$ \\
\hline 1 & $20 \mathrm{~min}$ & $20 \mathrm{~min}$ & $40 \mathrm{~min}$ & 3.11 \\
\hline 5 & $45 \mathrm{~min}$ & $20 \mathrm{~min}$ & $1 \mathrm{hr}: 05 \mathrm{~min}$ & 4.98 \\
\hline 10 & $1 \mathrm{hr}: 03 \mathrm{~min}$ & $20 \mathrm{~min}$ & $1 \mathrm{hr}: 23 \mathrm{~min}$ & 6.32 \\
\hline 50 & $2 \mathrm{hr}: 22 \mathrm{~min}$ & $20 \mathrm{~min}$ & $2 \mathrm{hr}: 42 \mathrm{~min}$ & 12.22 \\
\hline 100 & $3 \mathrm{hr}: 20 \mathrm{~min}$ & $20 \mathrm{~min}$ & $3 \mathrm{hr}: 40 \mathrm{~min}$ & 16.56 \\
\hline 150 & $4 \mathrm{hr}: 05 \mathrm{~min}$ & $20 \mathrm{~min}$ & $4 \mathrm{hr}: 25 \mathrm{~min}$ & 19.92 \\
\hline
\end{tabular}

${ }^{\mathrm{a}}$ Cost of one sampling per each crop area. 
field sizes. Therefore, for cotton, this sampling plan consists of direct counting of 58 samples of aphids on the leaves from the most apical cotton plant branches. Although only 20 min is necessary for evaluating these samples (evaluation time), the walking time between samples is the main factor responsible for the final sampling time and cost.

\section{ACKNOWLEDGEMENTS}

We thank the "Empresa de Pesquisa Estadual da Paraíba" (EMEPA) for providing the study area. We also thank the "Empresa Brasileira de Pesquisa Agropecuária" (EMBRAPA), the "Conselho Nacional de Desenvolvimento Científico e Tecnológico" (CNPq), the "Coordenação de Aperfeiçoamento de Pessoal de Nível Superior" (CAPES), Finance Code 001, and the "Fundação de Amparo à Pesquisa do Estado de Minas Gerais" (FAPEMIG) for the financial support provided. We also would like to thank Dr. Thomas E. Hunt, University of NebraskaLincoln, for assisting on the English revision.

\section{AUTHORS' CONTRIBUTIONS}

TAA, LHAA and CSB conceived the research. NRS and CEAL contributed material. TAA, EMS and MDM analysed the data. TAA, LHAA and FAS prepared and conducted experiments. TAA and CSB wrote the manuscript. CSB and MCP revised the manuscript.

\section{ORCID}

Tamíris A. Araújo (iD https://orcid.org/0000-0002-0582-9905

\section{REFERENCES}

Bacci, L., Picanço, M. C., Moura, M. F., Semeão, A. A., Fernandes, F. L., \& Morais, E. G. F. (2008). Sampling plan for Thrips (Thysanoptera: Thripidae) on cucumber. Neotropical Entomology, 37(5), 582-590. https://doi.org/10.1590/S1519-566X2008000500014

Bachmann, A. C., Nault, B. A., \& Fleischer, S. J. (2014). Alate aphid (Hemiptera: Aphididae) species composition and richness in northeastern USA snap beans and an update to historical lists. Florida Entomologist, 97(3), 979-994. https://doi.org/10.1653/024.097.0356

Bernays, A. (1994). Behavior: The process of host-plant selection. In A. Bernays, \& R. Chapman (Eds.), Host-plant selection by phytophagous insectsI (pp. 95-205). New York, NY: Chapman \& Hall.

Binns, M. R., Nyrop, J. P., \& Werf, W. V. D. (2000). Sampling and monitoring in crop protection: The theoretical basis for developing practical decision guides. New York, NY: CAB International.

Blackman, R. L., \& Eastop, V. F. (1984). Aphids on the world's crops: An identification guide. New York, NY: John Wiley \& Sons.

Bliss, C. I., \& Owen, A. R. G. (1958). Negative binomial distributions with a common k. Biometrika, 45(1/2), 37-58. https://doi. org/10.2307/2333044

Bueno, A. F., Batistela, M. J., Bueno, R. C. O. F., França-Neto, J. B., Nishikawa, M. A. N., \& Libério Filho, A. (2011). Effects of integrated pest management, biological control and prophylactic use of insecticides on the management and sustainability of soybean. Crop Protection, 30(7), 937-945. https://doi.org/10.1016/j. cropro.2011.02.021
CABI (2018). Crop protection compendium pest data sheet. [Online]. Retrieved from https://www.cabi.org/isc/datasheet/6204

Cao, C. W., Zhang, J., Gao, X. W., Liang, P., \& Guo, H. L. (2008). Overexpression of carboxylesterase gene associated with organophosphorous insecticide resistance in cotton aphids, Aphis gossypii (Glover). Pesticide Biochemistry and Physiology, 90(3), 175-180. https://doi.org/10.1016/j.pestbp.2007.11.004

Chamuene, A., Araújo, T. A., Silva, G., Costa, T. L., Berger, P. G., \& Picanço, M. C. (2018). Performance of the natural mortality factors of Aphis gossypii (Hemiptera: Aphididae) as a function of cotton plant variety and phenology. Environmental Entomology, 47(2), 440-447. https:// doi.org/doi.org/10.1093/ee/nvx205.

Cibils-Stewart, X., Sandercock, B. K., \& McCornack, B. P. (2015). Feeding location affects demographic performance of cabbage aphids on winter canola. Entomologia Experimentalis Et Applicata, 156(2), 49159. https://doi.org/10.1111/eea.12325

Corrêa, R. L., Silva, T. F., Simoes-Araujo, J. L., Barroso, P. A. V., Vidal, M. S., \& Vaslin, M. F. S. (2005). Molecular characterization of a virus from the family Luteoviridae associated with cotton blue disease. Archives of Virology, 150(7), 1357-1367. https://doi.org/10.1007/ s00705-004-0475-8

Fernandes, F. S., Ramalho, F. S., Malaquias, J. B., Nascimento Júnior, J. L., Correia, E. T., \& Zanuncio, J. C. (2012). Within-plant distribution of cotton aphid (Hemiptera: Aphididae) in cotton cultivars with colored fibers. Anais Da Academia Brasileira De Ciências, 84(3), 707-719. https://doi.org/10.1590/S0001-37652012005000040

Fernandes, M. G., Spessoto, R. R., Degrande, P. E., \& Rodrigues, T. R. (2011). Sequential sampling of Aphis gossypii Glover (Hemiptera: Aphididae) and Frankliniella schultzei Trybom (Thysanoptera: Thripidae) on cotton crop. Neotropical Entomology, 40(2), 258-263. https://doi.org/10.1590/S1519-566X2011000200016

Foresti, J., Bastos, C. S., Fernandes, F. L., \& Silva, P. R. D. (2018). Economic injury levels and economic thresholds for Leptoglossus zonatus (Dallas)(Hemiptera: Coreidae) infesting seed maize. Pest Management Science, 74(1), 149-158. https://doi.org/10.1002/ps.4671

Gallo, D., Nakano, O., Silveira Neto, S., Carvalho, R. P., Baptista, G. C. D., Berti Filho, E., ... Marchini, L. C. (2002). Entomologia agrícola (p. 920). Piracicaba, Brazil: FEALQ.

Herron, G. A., Powis, K., \& Rophail, J. (2001). Insecticide resistance in Aphis gossypii Glover (Hemiptera: Aphididae), a serious threat to Australian cotton. Australian Journal of Entomology, 40(1), 85-89. https://doi.org/10.1046/j.1440-6055.2001.00200.x

Jasrotia, P., Nataraja, M. V., Harish, G., Dutta, R., \& Savaliya, S. D. (2016). Effect of trap design and weather factors on relative efficiency of yellow sticky traps for sampling aphids in groundnut. Legume Research, 39(5), 834-839. https://doi.org/10.18805/Ir.v0iOF.9290

Kerns, D. L., Yates, J. A., \& Baugh, B. A. (2015). Economic threshold for cotton aphid (Hemiptera: Aphididae) on cotton in the southwestern United States. Journal of Economic Entomology, 108(4), 1795-1803. https://doi.org/10.1093/jee/tov161

Li, Z. Q., Zhang, S., Luo, J. Y., Wang, C. Y., Lv, L. M., Dong, S. L., \& Cui, J. J. (2013). Ecological adaption analysis of the cotton aphid (Aphis gossypii) in different phenotypes by transcriptome comparison. PLoS One, 8(12), e83180. https://doi.org/10.1371/journal.pone.0083180

Lima, C. H., Sarmento, R. A., Pereira, P. S., Galdino, T. V., Santos, F. A., Silva, J., \& Picanço, M. C. (2017). Feasible sampling plan for Bemisia tabaci control decision-making in watermelon fields. Pest Management Science, 73(11), 2345-2352. https://doi.org/10.1002/ps.4621

Malaquias, J. B., Ramalho, F. S., Dias, C. T. D. S., Brugger, B. P., Lira, A. C. S., Wilcken, C. F., ... Zanuncio, J. C. (2017). Multivariate approach to quantitative analysis of Aphis gossypii Glover (Hemiptera: Aphididae) and their natural enemy populations at different cotton spacings. Scientific Reports, 7(1), 41740. https://doi.org/10.1038/srep41740

Midgarden, D. G., Youngman, R. R., \& Fleischer, S. J. (1993). Spatial analysis of counts of Western corn rootworm (Coleoptera: Chrysomelidae) 
adults on yellow sticky traps in corn: Geostatistics and dispersion indices. Environmental Entomology, 22(5), 1124-1133. https://doi. org/10.1093/ee/22.5.1124

Miranda, J. A. (2010). Manejo integrado de pragas do algodoeiro no cerrado brasileiros - Circular Técnica $n^{\circ} 131$. Campina Grande, Brazil: EMBRAPA.

Moura, M. F., Lopes, M. C., Pereira, R. R., Parish, J. B., Chediak, M., Arcanjo, L. P., ... Picanço, M. C. (2018). Sequential sampling plans and economic injury levels for Empoasca kraemeri on common bean crops at different technological levels. Pest Management Science, 74(2), 398-405. https://doi.org/10.1002/ps.4720

Moura, M. F., Picanço, M. C., Guedes, R. N. C., Barros, E. C., Chediak, M., \& Morais, E. G. F. (2007). Conventional sampling plan for the green leafhopper Empoasca kraemeri in common beans. Journal of Applied Entomology, 131(3), 215-220. https://doi. org/10.1111/j.1439-0418.2006.01113.x

Naranjo, S. E., \& Castle, S. J. (2010). Sequential sampling plans for estimating density of glassy-winged sharpshooter, Homalodisca vitripennis (Hemiptera: Cicadellidae) on citrus. Crop Protection, 29(11), 1363-1370. https://doi.org/10.1016/j.cropro.2010.07.003

Pereira, P. S., Sarmento, R. A., Galdino, T. V. S., Lima, C. H. O., Santos, F. A., Silva, J., ... Picanço, M. C. (2016). Economic injury levels and sequential sampling plans for Frankliniella schultzei in watermelon crops. Pest Management Science, 73(7), 1438-1445. https://doi. org/10.1002/ps.4475

Pinto, B. C., Sarmento, R. A., Galdino, T. V. S., Pereira, P. S., Barbosa, B. G., Lima, C. H. O., ... Picanço, M. C. (2017). Standardized sampling plan for the Thrips Frankliniella schultzei (Thysanoptera: Thripidae) on watermelon crops. Journal of Economic Entomology, 110(2), 748-754. https://doi.org/10.1093/jee/tow314

Radcliffe, E. B., Hutchison, W. D., \& Cancelado, R. E. (2009). Integrated pest management: Concepts, tactics, strategies and case studies. Cambridge, UK: Cambridge University Press.

Ramalho, F. S., Fernandes, F. S., Nascimento, A. R. B., Nascimento Júnior, J. L., Malaquias, J. B., \& Silva, C. A. D. (2012). Feeding damage from cotton aphids, Aphis gossypii Glover (Hemiptera: Heteroptera: Aphididae), in cotton with colored fiber intercropped with fennel. Annals of the Entomological Society of America, 105(1), 20-27. https:// doi.org/10.1603/AN11122
Rosado, J. F., Sarmento, R. A., Pedro-Neto, M., Galdino, T. V., Marques, R. V., Erasmo, E. A., \& Picanço, M. C. (2014). Sampling plans for pest mites on physic nut. Experimental and Applied Acarology, 63(4), 521534. https://doi.org/10.1007/s10493-014-9804-0

Smith, C. M. (2005). Plant resistance to arthropods: Molecular and conventional approaches. Dordrecht, the Netherlands: Springer Science \& Business Media.

Smith, C. M., \& Chuang, W. P. (2014). Plant resistance to aphid feeding: Behavioral, physiological, genetic and molecular cues regulate aphid host selection and feeding. Pest Management Science, 70(4), 528540. https://doi.org/10.1002/ps.3689

Southwood, T. (1978). Ecological methods. New York, NY: Chapman \& Hall.

Taylor, L. R. (1961). Aggregation, variance and the mean. Nature, 189(4766), 732-735. https://doi.org/10.1038/189732a0

Young, L., \& Young, J. (1998). Statistical ecology: A population perspective. New York, NY: Springer US.

Zhang, P., Zhang, X., Zhao, Y., Ren, Y., Mu, W., \& Liu, F. (2015). Efficacy of granular applications of clothianidin and nitenpyram against Aphis gossypii (Glover) and Apolygus lucorum (Meyer-Dür) in cotton fields in China. Crop Protection, 78, 27-34. https://doi.org/10.1016/j. cropro.2015.08.012

\section{SUPPORTING INFORMATION}

Additional supporting information may be found online in the Supporting Information section at the end of the article.

How to cite this article: Araújo TA, Araújo LHA, Silva NR, et al. Standardized sampling plan for Aphis gossypii based on the cotton cultivar, plant phenology and crop size. J Appl Entomol. 2019;143:893-901. https://doi.org/10.1111/jen.12639 